\title{
O MANUSCRITO SEISCENTISTA DAS SAUDADES DE LIDIA E ARMIDO ATRIBUIDAS A BERNARDO VIEIRA RAVASCO
}

Marcelo Lachat

A Biblioteca Brasiliana Guita e José Mindlin da Universidade de São Paulo guarda em seu acervo uma raridade poética do século XVII: o manuscrito de um poema atribuído a Bernardo Vieira Ravasco (c. 1617-1697) ${ }^{1}$, irmão do Padre Antônio Vieira. Intitulado Saudades de Lídia e Armido, esse poema, composto de 158 oitavas em versos hendecassílabos $^{2}$, conserva-se em um códice manuscrito de 22,2 x 15,7 $\mathrm{cm}$, apógrafo e sem datação, constituído de dez fólios e encadernado em pleno marroquim vinho, sabendo-se que tal códice pertenceu ao

1. Não se sabe ao certo qual é a data de nascimento de Bernardo Vieira Ravasco, sendo que alguns autores afirmam que ele teria nascido em 1617 e outros em 1619. Já quanto ao ano de sua morte, parece não pairar qualquer dúvida, indicando-se sempre 1697.

2. Como ressalta Maria do Socorro Fernandes de Carvalho, "por todo o século XvII, em se tratando de verso, signo de engenho de agudeza é o hendecassílabo". Lembra ainda a estudiosa que a Arte Poetica e da Pintura e Symmetria, com Principios da Perspectiva (1615), de Philippe Nunes, "prestigia a contagem de todas as sílabas do verso, levando em conta aquela sílaba em que predomina o acento - voz da sílaba e alma das palavras, como diz -, mas considera também a sílaba breve ou as breves subsequentes" (Maria do Socorro Fernandes de Carvalho. Poesia de Agudeza em Portugal: Estudo Retórico da Poesia Lírica e Satírica Escrita em Portugal no Século xvı p. 230). Por isso, é mais adequado à preceptiva poética seiscentista considerar hendecassílabos (e não decassílabos) os versos dessas Saudades ditas de Bernardo Ravasco, compostas, como se presume, no século XVII. 
bibliófilo Rubens Borba de Moraes (1899-1986), como indica o ex-libris no verso da capa ${ }^{3}$. Sobre esse raro documento, informa o próprio Borba de Moraes:

Manuscrito em letra do século XviI em nosso poder. O poema é composto de 158 oitavas. É inédito.

Os versos de Bernardo Vieira Ravasco, nascido na Bahia em 1619, irmão do padre Vieira, ficaram quase todos inéditos. Barbosa Machado (vol. 1, p. 537) transcreve um soneto. Na Fênix Renascida e no Postilhão de Apolo, aparecem composições que lhe são atribuídas. Existem em bibliotecas portuguesas (na do Duque de Cadaval por exemplo), manuscritos contendo poesias desse poeta brasileiro tão apreciado em seu tempo ${ }^{4}$.

Na Enciclopédia de Literatura Brasileira, dirigida por Afrânio Coutinho e José Galante de Sousa, também é referido esse mesmo manuscrito: "Saudade (sic) de Lídia e Armido (poema ms. em letra do século XVII, pertencente a Rubens Borba de Moraes)" ${ }^{5}$. Assim, de acordo com esta Enciclopédia e com aquele trecho de Borba de Moraes, o códice das Saudades de Lídia e Armido atualmente depositado na Biblioteca Brasiliana Mindlin, embora não esteja datado, nem seja identificado seu compilador ou escriba e nem haja notícia acerca do lugar em que foi produzido, foi composto "em letra do século XVII". Essa asserção, ainda que não fundamentada nos dois casos, mostra-se pertinente quando se compara tal manuscrito com outros sabidamente seiscentistas. Nesse sentido, vale recorrer ao estudo de Vera Lúcia Costa Acioli, que caracteriza a escrita do século XVII e exemplifica com documentos. A pesquisadora assinala, então, que, na América Portuguesa, a escrita do Seiscentos "é, por assim dizer, a grande herdeira da usada em Portugal” e elenca suas principais características paleográficas e ortográficas, que são muito semelhantes às que se verificam no códice da BBM: "o d [aparece] com haste ascendente bem aberta e inclinada para a esquerda; $\mathbf{o} \mathbf{h}$, assemelhado a um $\mathbf{E}$ maiúsculo [em letra cursiva]; o st emendados por cima; $[. .$.$] o uso mais frequente de letras dobradas,$ agora também o c e o $\mathbf{m}$; a substituição do $\mathbf{i}$ por $\mathbf{j}$ e vice-versa; [...] separação irregular das palavras” ${ }^{6}$. Além dessas, outra peculiaridade do

\footnotetext{
Saudades / De Lidia \& Armido / Compostas por Bernardo Vieira \& Ravasco, São Paulo, RBBM (0710), 10 fls.

Rubens Borba de Moraes, Bibliografia Brasileira do Período Colonial, pp. 294-296.

Afrânio Coutinho e José Galante de Sousa (dir.), Enciclopédia de Literatura Brasileira, p. 1124.

Vera Lúcia Costa Acioli, A Escrita no Brasil Colônia: Um Guia para Leitura de Documentos Manuscritos, p. 133.
} 


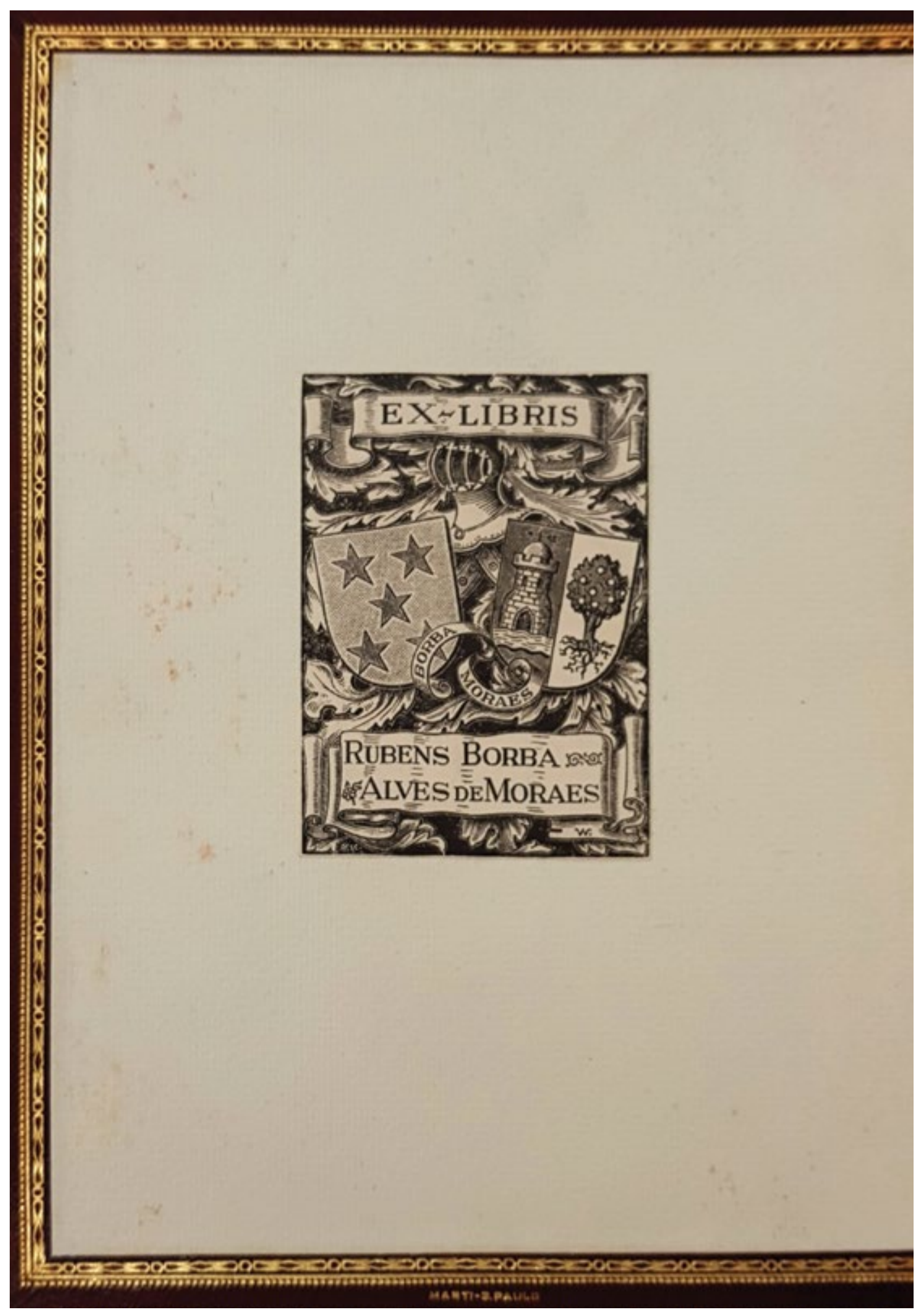


texto que permitiria situar sua escrita nos anos seiscentos são os sinais de pontuação: eles são substancialmente menos numerosos do que em documentos do Setecentos. Todavia, esses critérios possibilitam inferir uma data apenas aproximada (e nunca absoluta); daí se sugerir, neste trabalho, também levando em conta as circunstâncias históricas que cercam a persona poética Bernardo Ravasco, que o manuscrito apógrafo da Brasiliana foi redigido, possivelmente, entre meados e fins do século XVII.

Posterior a esse - e até muito recentemente não mencionado (ao que se saiba) por nenhum pesquisador -, há outro manuscrito em que se conservam, com poucas variantes, essas mesmas Saudades de Lídia e Armido atribuídas a Bernardo Ravasco. Trata-se de uma Miscelânea Poética setecentista depositada na Biblioteca da Ajuda, mais especificamente, seu quinto tomo, que foi compilado e escrito por Antônio Correia Vianna ${ }^{7}$ em Lisboa, em 1784, e do qual faz parte o referido poema ${ }^{8}$.

Somente em 2018, editaram-se e publicaram-se pela primeira vez, com base neste manuscrito da Biblioteca da Ajuda, mas cotejando-o com aquele da Brasiliana e registrando suas variantes, tais Saudades presumidamente compostas por Bernardo Ravasco 9 . No estudo que antecede essa edição, discutem-se as personae histórico-política e poética de Bernardo, bem como o poema. Desse modo, mostra-se que esse Vieira Ravasco foi, além de afamado poeta, importante persona política da América Portuguesa no século XVII, ocupando, de 1646 a 1697, o alto cargo de secretário do Estado do Brasil, hierarquicamente abaixo apenas do governador-geral. No entanto, ele foi (e ainda é) pouco estudado por pesquisadores da história ${ }^{10}$ e das letras luso-brasileiras e, muitas vezes, deixado à sombra de seu célebre irmão, o Padre Antônio Vieira.

7. É importante destacar que Correia Vianna é, no século xVII, um dos mais profícuos compiladores da poesia seiscentista, com diversas coleções manuscritas que têm muito a acrescentar à ainda pouco publicada e estudada produção poética - tanto portuguesa quanto luso-brasileira - do Seiscentos. Como apontado por Vítor Manuel de Aguiar e Silva, nos manuscritos de Correia Vianna encontram-se, por exemplo, muitos poemas inéditos atribuídos a uma reconhecida autoridade poética de Portugal no século xVII: Antônio da Fonseca Soares, isto é, Frei Antônio das Chagas (cf. Vítor Manuel de Aguiar e Silva, Maneirismo e Barroco na Poesia Lírica Portuguesa, pp. 533-544).

8. Saudades / de / Lidia, e Armido / Expostas na figura de Ella ficar saudosa / e magoada em terra, por Elle se ausentar / embarcando em huma Armada \& a / Compostas / Por Bernardo Vieira Ravasco / Irmão do grde. Pe. Ant. ${ }^{\circ}$ Vieyra / da extincta Companhia de lesus. In: Miscelanea Poetica / que comprehende / o que na seguinte página se declára. Tomo $=5^{\circ}$. Junto tudo neste volume, destribuîdo, e escrito / Por Antonio Correya Vianna $/$ Lisboa = 1784 =. Lisboa, Biblioteca da Ajuda, ms. 49-III-65, pp. 173-256 (A paginação dessa Miscelânea foi feita pelo próprio compilador)

9. Marcelo Lachat, Saudades de Lídia e Armido, Poema Atribuído a Bernardo Vieira Ravasco: Estudo e Edição.

10. Pedro Puntoni é um dos raros historiadores que têm se dedicado a estudar, cuidadosamente, essa persona histórico-política, destacando-se seu trabalho intitulado "Bernardo Vieira Ravasco, Secretário do Estado do Brasil: Poder e Elites na Bahia do século xvı" (Pedro Puntoni, O Estado do Brasil: Poder e Política na Bahia Colonial 1548-1700, pp. 199-241). 
Um primeiro catálogo conhecido das supostas obras de Bernardo Ravasco - e que visa a comprovar a excelência dessa persona nas letras - é o apresentado, no século XviII, na Biblioteca Lusitana de Diogo Barbosa Machado ${ }^{11}$ :

Descrição Topográfica, Eclesiástica, Civil, e Natural do Estado do Brasil (Barbosa Machado afirma possuir dessa obra uma "parte escrita da própria mão do Autor com estilo discreto e elegante", e transcreve o trecho inicial de tal parte); Poesias Portuguesas e Castelhanas (compostas em vários metros, estariam reunidas em quatro tomos manuscritos, "da própria mão do $\mathrm{Au}-$ tor”, como teria visto o irmão de Diogo Barbosa Machado, o "Doutor Inácio Barbosa Machado, quando exercitava o lugar de Juiz de fora, e Provedor da Cidade da Bahia"); Três Decimas à Senhora D. Isabel Princesa de Portugal Tendo Morto em Salvaterra de um Tiro a um Javali (impressas no quinto tomo da Fênix Renascida, em 1728). Além desses escritos, a Biblioteca Lusitana atribui ainda a Bernardo Ravasco um soneto castelhano que teria saído impresso em uma obra intitulada Coleção Política de Apotegmas Memoráveis, transcrevendo o poema "para se conhecer claramente a facilidade da sua Musa [...] que fez estando no Paço à petição de Domingos de Aguiar Porteiro da Câmara da Rainha, acerca de um Papagaio que se oferecia à mesma Senhora, em o qual compete a discrição com a elegância”. Contudo, esse mesmo soneto (com variações mínimas) foi publicado no terceiro tomo da Fênix Renascida, tendo como didáscalia A um papagaio de Palácio, que falava muito e sem qualquer atribuição de autoria; curiosamente, Barbosa Machado não faz menção a esse fato, talvez para não colocar em dúvida a auctoritas poética do Ravasco ${ }^{12}$.

Quanto ao Bernardo poeta, em particular, afora as três décimas impressas no quinto tomo da Fênix Renascida e mencionadas por Barbosa Machado, outro poema, composto de dez oitavas, é atribuído a essa persona poética na outra grande coletânea de poesia portuguesa seiscentista publicada no século XviII, o Postilhão de Apolo. Tal poema, que tem como didascália "De Bernardo Vieira / Pelos mesmos consoantes / apllicando-as [sic] a hum Cadaver" ${ }^{13}$, glosa a temática do memento mori e forma com o texto que o antecede na mesma coleção setecentista, isto é, o Retrato de Huma Dama feito em oitavas por Eusébio de Matos (talvez não por acaso, o padre e irmão de Gregório de Matos), um díptico poético.

\footnotetext{
11. Cf. Diogo Barbosa Machado, Bibliotheca Lusitana, tomo I, pp. 538-539.

2. Marcelo Lachat, op. cit., pp. 31-32.

13. Eccos Que o Clarim da Fama Dá: Postilhaõ de Apollo, pp. 256 e ss.
} 
Esses dois poemas, ou seja, aquelas décimas da Fênix Renascida e essas oitavas do Postilhão de Apolo (desconsiderando-se, pelo motivo já explicitado, aquele soneto Íris Parlera, Abril Organizado) compunham, até meados do século xx, todo o corpus poético impresso de Bernardo Ravasco. Porém, James Amado, em sua edição de grande parte da poesia manuscrita dita de Gregório de Matos, intitulada pelo editor Crônica do Viver Baiano Seiscentista: Obra Poética Completa, publicou uma suposta disputa poética entre Gregório e Bernardo, na qual há mais dois textos: dois sonetos com atribuição ao poeta Ravasco ${ }^{14}$. Mais recentemente, João Adolfo Hansen e Marcello Moreira editaram o Códice Asensio-Cunha, com poemas atribuídos a Gregório de Matos, entre os quais também se encontram os sonetos (quatro no total, sendo dois de cada poeta) que constituem tal certame poético ${ }^{15}$. Todavia, não é essa a única disputa poética em que, presumidamente, o poeta Bernardo esteve envolvido; outra, mais conhecida, teria ocorrido entre ele e seu irmão. Esse segundo certame é referido, por exemplo, por João Carlos Teixeira Gomes ${ }^{16}$ e João Adolfo Hansen ${ }^{17}$, iniciando-se por um "soneto de Bernardo Vieira Ravasco, Secretário do Estado do Brasil, a seu irmão o Padre Antônio Vieira, consoantes forçados”.

Posto isso, cabe salientar, então, que o corpus poético impresso atribuído a Bernardo Ravasco resume-se, atualmente, a estes cinco poemas citados mais aquelas Saudades de Lídia e Armido publicadas apenas em 2018. Contudo, o corpus manuscrito dessa persona é mais extenso, havendo textos inéditos a serem estudados e dados a público. Trata-se, dessa maneira, de um poeta cuja auctoritas ainda precisa ser materialmente consolidada, escavando-se as ruínas letradas luso-brasileiras dos séculos XVII e XVIII. Por isso, esse Ravasco raramente aparece nos compêndios de literatura brasileira ou portuguesa e sua persona poética e sua obra, quando mencionadas, são discutidas de forma bastante superficial.

Fica evidente, portanto, a importância do manuscrito seiscentista depositado na Biblioteca Brasiliana, no qual se preservam essas Saudades ditas do poeta Bernardo. Tal códice consiste em um documento essencial para um melhor conhecimento e uma mais fundamentada discussão das letras (particularmente da poesia) na América Portuguesa dos anos seiscentos. Ademais, deve-se acrescentar que a relevância

\footnotetext{
14. Gregório de Matos, Crônica do Viver Baiano Seiscentista: Obra Poética Completa; Códice James Amado, vol. I, pp. 188-189.

15. Gregório de Matos, Poemas Atribuídos: Códice Asensio-Cunha, vol. 1, pp. 381-384.

16. Cf. Gregório de Matos, o Boca de Brasa - um Estudo de Plágio e Criação Intertextual, pp. 258 e ss.

17. Cf. A Sátira e o Engenho: Gregório de Matos e a Bahia do Século xvII, pp. 60-61.
} 
do códice da Brasiliana mostra-se, ainda, no fato de tratar-se de uma fonte manuscrita que circulou, provavelmente, a partir da segunda metade do século XVII no Estado do Brasil (conjecturando-se o lugar em que foi composta), enquanto a outra fonte, sabidamente produzida por Correia Vianna, já é do último quartel do século XviII e sua circulação deu-se em Portugal. Entretanto, em vez de determinar, de forma anacrônica e segundo critérios sempre questionáveis, qual dos dois manuscritos é mais "autêntico" 18 , interessa antes notar que essas Saudades de Lídia e Armido tiveram considerável recepção nas letras portuguesas e luso-brasileiras, atribuindo-se-lhes a auctoritas poética da persona histórica Bernardo Vieira Ravasco desde, aproximadamente, a segunda metade do Seiscentos. E tal autoridade se atesta, em última instância, pela excelência do poema.

Assim, cabe lembrar que as "saudades" sofridas por Lídia e Armido foram cantadas diversas vezes, por diferentes poetas, nos anos seiscentos e setecentos. Na Fênix Renascida, por exemplo, há três longos poemas, em oitavas, intitulados "Saudades de Lydia", e Armido. Trata-se de topos largamente glosado na poesia seiscentista, síntese da dolorosa e triste separação entre entes queridos que, motivada pela Guerra da Restauração (1640-1668) durante o reinado de D. João IV (1640-1656), moveu à compaixão alguns "engenhos poéticos”, representando-se, principalmente nas personae Armido e Lídia, a "lastimosa partida" do amante-amado para combater na guerra e as saudades ou sofrimentos da amada-amante.

Especificamente, as Saudades de Lídia e Armido atribuídas a Bernardo Ravasco ressaltam sua auctoritas poética por ser esse poema uma excelente imitação (mimesis, imitatio) que, com estilo agudo e doutrina vária, faz do amor agudezas. Entre seus mais relevantes modelos, destacam-se o Camões de Os Lusíadas e o Góngora da Fábula de Polifemo y Galatea e das Soledades. De acordo com alguns estudiosos ${ }^{19}$, as Soledades castelhanas (não apenas, mas principalmente essas gongóricas) são o grande paradeigma poético das Saudades portuguesas; e as supostamente compostas pelo poeta Ravasco, em especial, mostram-se agudas já na sua primeira oitava, com versos que, emulando o Camões épico e o Góngora lírico, cantarão matéria trágico-amorosa:

\footnotetext{
18. Adotam-se aqui as críticas de Marcello Moreira ao método filológico lachmanniano, o qual se pretende "como o meio de recuperação de um ideal textual que se supõe ter existido, embora não haja provas materiais conclusivas de sua existência" (Critica textualis in caelum revocata? Uma Proposta de Edição e Estudo da Tradição de Gregório de Matos e Guerra, p. 53). Como ainda adverte Moreira, baseando-se em Morse Peckham, há uma propensão entre os filólogos caudatários desse método de "instituir uma hagiografia de autores e, como consequência dessa santificação, quanto mais próximos os textos estiverem do autor, mais preciosos e puros estarão, tornando-se verdadeiras relíquias" (Idem, p. 56). Neste artigo, evita-se justamente tal idealização ou santificação.

19. Cf. José Ares Montes. Góngora y La Poesía Portuguesa del Siglo xvII, pp. 386-448.
} 


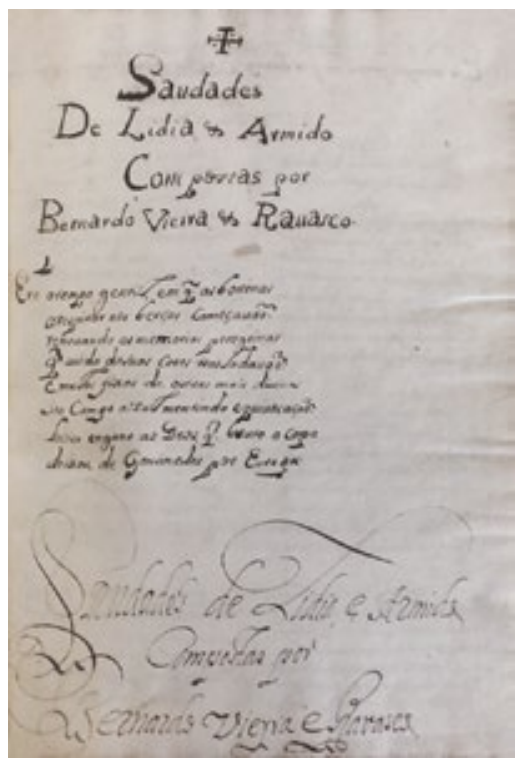

Frontispício e fólios 1 e 10v do manuscrito seiscentista das Saudades / de Lidia \& Armindo / Compostas por Bernardo Vieira \& Ravasco, depositado na Biblioteca Brasiliana Guita e José Mindlin na Universidade de São Paulo.
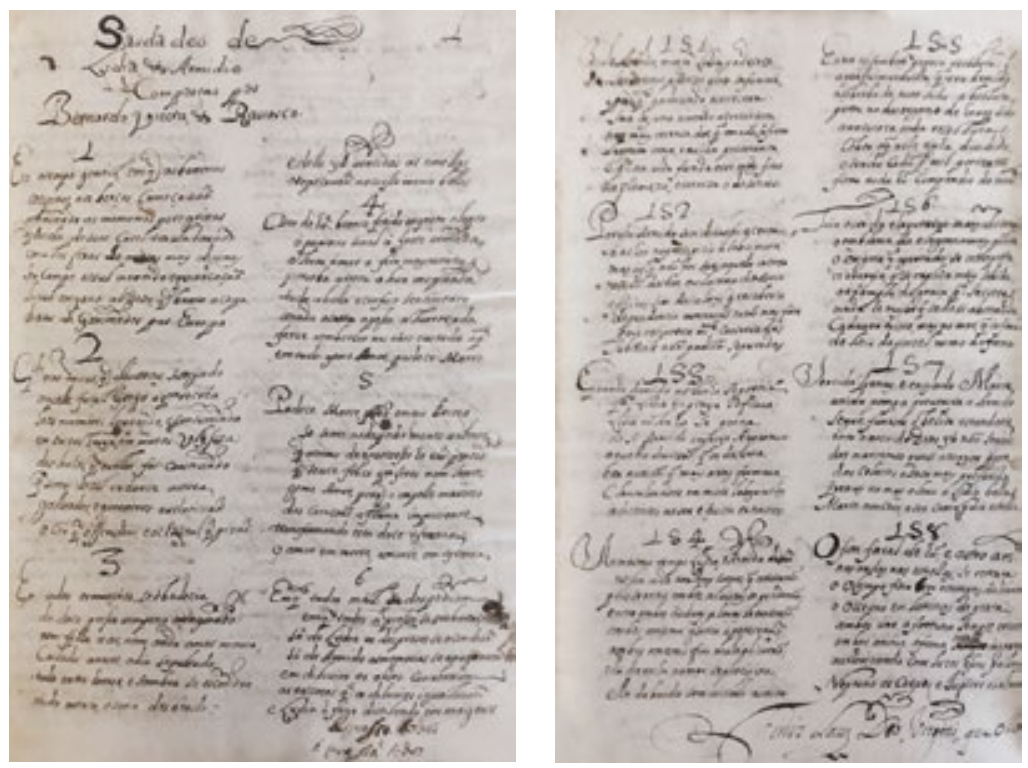
Era o tempo gentil, em que as boninas

a respirar no berço começavam,

renovando as memórias peregrinas,

que a vida de suas cores trasladavam:

Êmulas fixas de outras mais divinas,

seu campo azul mentido equivocavam;

Lascivo engano ao Deus, que bruto, a Copa

deixou de Ganimedes por Europa ${ }^{20}$.

Nesse trecho, ecoam os versos da oitava 72 do Canto II de Os Lusía$d_{a s^{21}}$ e da primeira estância das Soledades de Góngora ${ }^{22}$. Dessa forma, compreende-se melhor o "tempo gentil" em que se inicia o poema atribuído a Bernardo Ravasco: consiste no "tempo alegre" do verso camoniano ou na "estación florida" do gongórico, isto é, refere-se à primavera, ou melhor, ao princípio dessa estação florida, quando as boninas começam a surgir no campo, mudando-se suas cores. E essas boninas, devido às suas vivas cores ou ao seu intenso brilho, são "êmulas fixas" das estrelas, fazendo com que o campo seja um falso ("mentido") céu. Zeus, caindo nesse lascivo engano, abandonou Ganimedes que, raptado e violado pelo "pai dos homens e dos deuses" 23 e infiel marido de Hera metamorfoseado em águia, era o responsável pela "copa” dos deuses no Olimpo; abandonou Ganimedes, descendo de sua divina morada, para tomar a forma de touro ("bruto") e também raptar e violar Europa. Portanto, essa referência mitológica, na esteira daquelas da mencionada oitava de Os Lusíadas e dos versos das Soledades, confirma que o "tempo gentil” é a primavera, mais especificamente, abril, quando o sol entra na constelação de touro.

Não é propósito deste artigo estender-se na análise dessas Saudades de Lídia e Armido, porque isso já foi feito em outro trabalho ${ }^{24}$, e sim evidenciar a relevância do manuscrito seiscentista em que se registrou tal poema excelentemente agudo. Preserva-se nesse códice da Biblioteca Brasiliana, e comprova-se com ele, a auctoritas poética que Bernardo

\footnotetext{
20. Marcelo Lachat, op. cit., p. 100.

21. "Era no tempo alegre quando entrava / No roubador de Europa a luz Febeia, / Quando um e o outro corno Ihe aquentava, / E Flora derramava o de Amalteia. / A memória do dia renovava / O pressuroso Sol, que o Céu rodeia, / Em que Aquele a quem tudo está sujeito / O selo pôs a quanto tinha feito" (Luís de Camões, Obra Completa, p. 50).

22. "Era del año la estación florida / en que el mentido robador de Europa / (media luna las armas de su frente, / y el Sol todos los rayos de su pelo), / luciente honor del cielo, / en campos de zafiro pace estrellas, / cuando el que ministrar podía la copa / a Júpiter mejor que el garzón de Ida, / náufrago y desdeñado, sobre ausente, / lagrimosas de amor dulces querellas / da al mar, que condolido, / fue a las ondas, fue al viento / el mísero gemido, / segundo de Arión dulce instrumento" (Luis de Góngora, Soledades, pp.75-76).

23. É esse um dos epítetos de Zeus na Teogonia de Hesíodo (v. 542).

24. Marcelo Lachat, op. cit., pp. 60-87.
} 
Vieira Ravasco tinha no século XviI e que se perdeu nos séculos seguintes entre papéis mal conservados ou mal compulsados. Historicamente apagado sob a sombra de seu ilustre irmão Antônio, reluz, enfim, o poeta Bernardo nessas manuscritas Saudades seiscentistas.

\section{SOBRE 0 AUTOR}

Marcelo Lachat é doutor em Literatura Portuguesa pela Universidade de São Paulo (USP). Professor do Departamento de Letras da Universidade Federal de São Paulo (Unifesp). É colíder do grupo de pesquisa "Historiografia das Letras Luso-Brasileiras e da Literatura Brasileira” (Unifesp/UsP). Entre suas publicações, destaca-se o livro Saudades de Lídia e Armido, Poema Atribuído a Bernardo Vieira Ravasco: Estudo e Edição (São Paulo: Alameda, 2018). 


\section{O MANUSCRITO SEISCENTISTA DAS SAUDADES DE LIDIA E ARMIDO ATRIBUÍDAS A BERNARDO VIEIRA RAVASCO $p .72$}

RESUMO No acervo da Biblioteca Brasiliana Guita e José Mindlin, encontra-se um manuscrito seiscentista das Saudades de Lídia e Armido, poema composto de 158 oitavas e atribuído a Bernardo Vieira Ravasco (c. 1617-1697), irmão do Padre Antônio Vieira. Neste artigo, buscase evidenciar a importância desse manuscrito para a historiografia das letras luso-brasileiras do século XVII. BERNARDO VIEIRA RAVASCO

- MANUSCRITO - POESIA SEISCENTISTA • LETRAS

LUSO-BRASILEIRAS.

\section{THE SEVENTEETH-CENTURY MANUSCRIPT OF SAUDADES DE LÍDIA E ARMINDO, POEM ATTRIBUTED TO BERNARDO VIEIRA RAVASCO}

ABSTRACT In the collection of the Biblioteca Brasiliana Guita e José Mindlin, there is a 17th century manuscript of Saudades de Lídia e Armido, poem composed of 158 octaves and attributed to Bernardo Vieira Ravasco (c.16171697), Father Antonio Vieira's brother. In this paper, we try to highlight the importance of this manuscript for the historiography of 17 th century LusoBrazilian letters. BERNARDO VIEIRA RAVASCO • MANUSCRIPT • 17TH CENTURY POETRY • LUSO-BRAZILIAN LETTERS

\section{REFERÊNCIAS}

Acioli, Vera Lúcia Costa. A Escrita no Brasil Colônia: Um Guia para Leitura de Documentos Manuscritos. Recife, Editora da UFPE; Fundação Joaquim Nabuco; Massangana, 1994.

A Fenix Renascida ou Obras Poeticas dos Melhores Engenhos Portuguezes. Segunda vez impresso e acrescentado por Mathias Pereira da Sylva. 5 tomos. Lisboa: Offic. dos Herd. de Antonio Pedrozo Galram, 1746.

Aguiar a Silva, Vítor Manuel de. Maneirismo e Barroco na Poesia Lírica Portuguesa. Coimbra, Centro de Estudos Românicos, 1971.

CAMÕEs, Luís de. Obra Completa. Organização, introdução, comentários e anotações de Antônio Salgado Júnior. Rio de Janeiro, Nova Aguilar, 2005.

Carvalho, Maria do Socorro Fernandes de. Poesia de Agudeza em Portugal: Estudo Retórico da Poesia Lírica e Satírica Escrita em Portugal no Século XVII. São Paulo, Humanitas, Edusp, Fapesp, 2007.

Coutinho, Afrânio \& Sousa, José Galante de (dir.). Enciclopédia de Literatura Brasileira. vol. 2. Brasília, Fundação de Assistência ao Estudante (FAE) - Ministério da Educação e do Desporto, 1995.

Eccos Que o Clarim da Fama Dá: Postilhaõ de Apollo. 2 tomos. Por Joseph Maregelo de Osan. Lisboa: Na Offic. de Francisco Borges de Souza, 1761-1762.

Gomes, João Carlos Teixeira. Gregório de Matos, o Boca de Brasa - Um Estudo de Plágio e Criação Intertextual. Petrópolis, Vozes, 1985.

GóNGORA, Luis de. Soledades. Edición de John Beverley. Madrid, Cátedra, 2007.

HANSEn, João Adolfo. A Sátira e o Engenho: Gregório de Matos e a Bahia do Século Xvir. 2. ed. rev. São Paulo, Ateliê Editorial; Campinas, Editora da Unicamp, 2004.

HEsíodo. Teogonia. Tradução de Jaa Torrano. São Paulo, Iluminuras, 2006.

LAchat, Marcelo. Saudades de Lídia e Armido, Poema Atribuído a Bernardo Vieira Ravasco: Estudo e Edição. São Paulo, Alameda, 2018.

Machado, Diogo Barbosa. Bibliotheca Lusitana. Tomo I. Lisboa Occidental, Na Officina de Antonio Isidoro da Fonseca, 1741. 
Matos, Gregório de. Crônica do Viver Baiano Seiscentista: Obra Poética Completa; Códice James Amado. 2 vols. 4. ed. Rio de Janeiro, Record, 1999.

Poemas Atribuídos: Códice Asensio-Cunha. 5 vols. Edição e estudo de João Adolfo Hansen e Marcello Moreira. Belo Horizonte, Autêntica, 2013.

Montes, José Ares. Góngora y La Poesía Portuguesa del Siglo XVII. Madrid, Gredos, 1956.

Moraes, Rubens Borba de. Bibliografia Brasileira do Período Colonial: Catálogo Comentado das Obras dos Autores Nascidos no Brasil e Publicadas Antes de 1808. São Paulo, IEB-USP, 1969.

Moreira, Marcello. Critica Textualis in Caelum Revocata? Uma Proposta de Edição e Estudo da Tradição de Gregório de Matos e Guerra. São Paulo, Edusp, 2011.

Puntoni, Pedro. "Bernardo Vieira Ravasco, Secretário do Estado do Brasil: Poder e Elites na Bahia do século xviı”. O Estado do Brasil: Poder e Política na Bahia Colonial 1548-1700. São Paulo, Alameda, 2013, pp. 199-241.

Saudades / De Lidia \& Armido / Compostas por Bernardo Vieira \& Ravasco. São Paulo, RBBM (0710), 10 fls.

Saudades / de / Lidia, e Armido / Expostas na figura de Ella ficar saudosa / e magoada em terra, por Elle se ausentar / embarcando em huma Armada \& ${ }^{a}$ / Compostas / Por Bernardo Vieira Ravasco / Irmão do grde. Pe. Ant. ${ }^{o}$ Vieyra / da extincta Companhia de Iesus. In: Miscelanea Poetica / que comprehende / o que na seguinte página se declára. Tomo $=5^{\circ}$. Junto tudo neste volume, destribuîdo, e escrito / Por Antonio Correya Vianna / Lisboa = 1784 =. Lisboa: Biblioteca da Ajuda, ms. 49-III-65, pp. 173-256. 